\title{
IMPLEMENTAÇÃO DAS SALAS DE RECURSOS MULTIFUNCIONAIS: TEMPOS VIVIDOS E VIVENCIADOS.
}

\author{
IMPLEMENTACIÓN DE LAS SALAS DE RECURSOS MULTIFUNCIONALES: \\ TIEMPOS VIVOS Y EXPERIMENTADOS
}

\section{IMPLEMENTATION OF MULTIFUNCTIONAL RESOURCE CLASSES: LIFE AND EXPERIENCE}

\author{
Ana Paula SILVEIRA ${ }^{1}$ \\ Adriana Maria SILVA ${ }^{2}$ \\ Ângela Márcia MORCELI ${ }^{3}$
}

RESUMO: Este relato de experiência fora escrito por profissionais atuantes no Atendimento Educacional Especializado, nos anos de 2014 a 2017, a fim de ilustrar aos leitores o processo de implementação da primeira sala de Recursos Multifuncionais, no município de Arraial das Flores, servindo de ilustrações para futuras instalações e implementações. A intenção desse relato é apresentar como foram as experiências vividas nas primeiras salas de Atendimento Educacional Especializado na cidade de Arraial das Flores, apresentando toda trajetória desde a organização do espaço - com os materiais disponibilizado pelo Governo Federal até o funcionamento da sala de AEE, discorrendo sobre as duas salas que possibilitaram meios e recursos, ao desenvolvimento da aprendizagem do estudante com deficiência. Para realização do relato de experiência fora feita uma revisão de bibliografia na área afim, contendo embasamento teórico, além das experiências vividas pelas profissionais atuantes no Atendimento Educacional Especializado no dado munícipio. Vale ressaltar que a implementação aconteceu de acordo com os preceitos legais, assegurando Atendimento Educacional Especializado a todas as crianças com deficiência, regularmente matriculados nas escolas municipais.

PALAVRAS-CHAVE: Atendimento educacional especializado. Sala de recursos. Aprendizagens significativas.

RESUMEN: Este informe de experiencia fue escrito por profesionales que trabajan en el Servicio Educativo Especializado, de 2014 a 2017, para ilustrar a los lectores el proceso de implementación de la primera sala de Recursos Multifuncionales en el municipio de Arraial das Flores, que sirve como ilustraciones para el futuro instalaciones e implementaciones. La intención de este informe es presentar las experiencias vividas en las primeras salas del Servicio Educativo Especializado en la ciudad de Arraial das Flores, presentando toda la

${ }^{1}$ Universidade Federal de São Carlos (UFSCAR), São Carlos - SP - Brasil. Doutoranda no Programa de Pósgraduação em Educação. ORCID: https://orcid.org/0000-0002-6761-9807. a_silveirapaula@yahoo.com.br

${ }^{2}$ Uniasselvi, Ribeirão Preto - SP - Brasil. Graduanda no Curso de Libras ORCID: https://orcid.org/0000-00025551-6472. E-mail: drika.letras13@yahoo.com.br

${ }^{3}$ Instituto Municipal de Ensino Superior de Bebedouro Victório Cardassi (IMESB), Bebedouro - SP - Brasil. Graduanda no Curso de Direito. ORCID: https://orcid.org/0000-0002-0172-0259. E-mail: angelamorcelli@hotmail.com 
trayectoria desde la organización del espacio, con los materiales puestos a disposición por el Gobierno Federal para el funcionamiento de la sala de la SEE, discutiendo sobre las dos salas que hicieron posibles medios y recursos, para el desarrollo del aprendizaje de estudiantes con discapacidades. Para llevar a cabo el informe de experiencia, se realizó una revisión bibliográfica en el área relacionada, que contiene antecedentes teóricos, además de las experiencias vividas por los profesionales que trabajan en el Servicio Educativo Especializado del municipio. Vale la pena mencionar que la implementación se realizó de acuerdo con los preceptos legales, asegurando la Asistencia Educativa Especializada a todos los niños con discapacidades, inscritos regularmente en las escuelas municipales.

PALABRAS CLAVE: Servicio educativo especializado. Sala de recursos. Aprendizaje significativo.

ABSTRACT: This experience report was written by professionals working in the Specialized Educational Assistance in order to illustrate to the readers the process of implementing the first Specialized Education Assistance (SEA) room in the city of Arraial das Flores, serving as a guide for future installments and implementations. The intention of this report is to present the experience of the first rooms of Specialized Educational Assistance in the city of Arraial das Flores, trying to show all the way from the beginning (space organization - with the materials provided by the Federal Government) to the SEA room, discussing the two rooms that provides means and resources for the development of learning of students with disabilities. For the realization of the experience report, a bibliography review was done in the related area to contain theoretical background, as well as the experiences of professionals working in the Specialized Educational Assistance in the given municipality. It is worth mentioning that the implementation took place according to the legal precepts, ensuring Specialized Educational Assistance to all children with disabilities, regularly enrolled in municipal schools.

KEYWORDS: Specialized educational assistance. Resource room. Significant learning.

\section{Introdução}

O presente relato de experiência traz as experiências, os resultados e as expectativas em relação a primeira sala de recursos multifuncionais do município de Arraial das Flores, que fica localizada na região noroeste do Estado de São Paulo.

Para a realização de desse relato valemo-nos dos métodos de levantamento e revisão bibliográfica, para a descrição analítica, inicialmente houve a leitura e interpretação do encontrado na área da educação especial, houve uma seleção criteriosa dos artigos acadêmicos, livros, documentos federais que contemplassem a nossa proposição em escrever um relato de experiência acerca da sala de recursos, em que compartilharíamos as nossas práticas, refletindoas para que pudéssemos encontrar os resultados, desses dois anos de AEE, em Arraial das Flores. 
Vale ressaltar que utilizaremos nomes de personagens da literatura brasileira e portuguesa para identificar as escolas, para não gerarmos constrangimentos aos envolvidos com a proposta de implementação da sala de recursos multifuncionais em um município do interior do estado de São Paulo.

A sala de recursos multifuncionais teve início em junho de 2014, na Escola Municipal Guimarães Rosa, em 2016 a segunda sala de recursos foi criada na Escola Municipal Fernando Pessoa.

No início dos trabalhos as incertezas cerceavam a prática docente, mas com o passar do tempo as incertezas foram concretizadas em práticas bem sucedidas, como será apresentado ao longo desse texto, para que pudéssemos escrevê-lo houve a apresentação deste como Proposta de Estrutura e Funcionamento da Sala de Recursos Multifuncionais à Secretária de Educação, como prescrito na legislação que fundamenta o Atendimento Educacional Especializado (AEE) no Brasil. Nesse sentido o presente relato de experiência é a proposta do AEE do município supracitado, juntamente com as práticas e suas reflexões, para a composição deste relato de experiência.

Os desafios em relação ao Atendimento Educacional Especializado nas escolas públicas são inúmeros, porém os desafios não impedem que as pessoas com deficiências tenham seus direitos assegurados, tais desafios podem ser exemplificados como a ausência de materiais, a ausências de compreensões pelos profissionais da educação básica do que se trata o Atendimento Educacional Especializado e a disponibilidade de horários para atender com qualidade o maior número possível de pessoas com deficiência, entre outros que se fossem aqui mensurados escreveríamos um outro relato de experiências.

\section{Atendimento educacional especializado}

O AEE ocorre dentro das Salas de Recursos Multifuncionais, de acordo com a Resolução n. ${ }^{\circ}$ 4, de 2 de Outubro de 2009, esse atendimento é destinado a pessoas com deficiências, com transtornos globais do desenvolvimento, altas habilidades/superdotação, matriculados em classe comum do ensino regular, assegurando-lhes condições de acesso, participação e aprendizagem.

Estudantes com deficiência - aqueles que têm impedimentos de longo prazo de natureza física, intelectual, mental ou sensorial, os quais, em interação com diversas barreiras, podem ter obstruída sua participação plena e efetiva na escola e na sociedade; 
Estudantes com transtornos globais do desenvolvimento - aqueles que apresentam quadro de alterações no desenvolvimento neuropsicomotor, comprometimento nas relações sociais, na comunicação e/ou estereotipias motoras. Fazem parte dessa definição estudantes com autismo infantil, síndrome de Asperger, síndrome de Rett, transtorno desintegrativo da infância;

Estudantes com altas habilidades ou superdotação - aqueles que apresentam potencial elevado e grande envolvimento com as áreas do conhecimento humano, isoladas ou combinadas: intelectual, acadêmica, liderança, psicomotora, artes e criatividade (BRASIL, 2009, p. 1).

Os estudantes com deficiências, no contra turno devem frequentar o AEE, para que haja o suporte pedagógico necessário ao ensino regular, para o desenvolvimento das potencialidades.

Criam-se numerosas expectativas e especulações acerca do trabalho desenvolvido durante o AEE, como por exemplo, a falta de entendimento do que se trata o AEE, a ausência de práticas docentes e a superação de desafios para as pessoas com deficiências e seus familiares.

As primeiras atividades do AEE no município Arraial das Flores foram em 2014 e se constituíram na visita em todas as unidades de ensino (oito unidades) para a coleta informações sobre os estudantes com deficiências matriculados no Ensino Fundamental de nove anos, sobretudo do $1^{\mathrm{o}}$ ao $5^{\mathrm{o}}$ ano.

Essas visitas técnicas consistiram em ouvir as necessidades dos profissionais da educação em relação a educação especial, além de realizar algumas conversas com os responsáveis dos estudantes, esclarecendo as dúvidas, enfatizando que que práticas educacionais individualizadas trariam as possibilidades de as crianças conseguirem assimilar, abstrair, compreender melhor os conteúdos propostos no ensino regular.

Enquanto faziam-se as visitas nas Escolas, simultaneamente, ocorria o estudo dos materiais e documentos dispostos pelo Ministério da Educação (MEC), como Documento Orientador: programa de implementação de Salas de Recursos Multifuncionais (2012), destinado às unidades de ensino, esse documento contém as normas para organização dos espaços, orientações para a matrícula dos estudantes, nomeação e funcionalidade dos equipamentos de informática, garantindo o usufruto da tecnologia assistiva e apresentação dos materiais didáticos pedagógicos.

Nesse sentido a implementação destas salas de recursos multifuncionais em âmbito nacional responde a uma necessidade histórica, pois é notória uma lacuna entre o desenvolvimento cognitivo e a ausência do acesso a uma educação de qualidade, em se tratando de educação especial. 
Os sujeitos com necessidades especiais nesse atendimento podem gozar de aprendizagens significativas, as quais buscam respeitar suas limitações e desenvolver suas potencialidades, permitindo que o processo de inclusão em salas regulares se dê de maneira dialética, entre o AEE e o ensino regular, como proposto pela Resolução $n^{\circ} 4$, de 2 de Outubro de 2009.

As unidades de ensino que receberam a sala de recursos multifuncional para o atendimento especializado precisam respeitar e aceitar as modificações necessárias para o ato, pois;

Em ambas as circunstancias, o que fica evidenciado é a necessidade de se redefinir e de se colocar em ação novas alternativas e práticas pedagógicas, que favorecem a todos os alunos, o que implica na atualização e desenvolvimento de conceitos e em aplicações educacionais compatíveis com esse grande desafio (MONTOAN, 2007).

A inclusão está posta no contraste entre o velho e o novo na instituição escolar, pois ao mesmo tempo em que temos propostas pedagógicas subsidiadas por tecnologias entre outras, ainda tem-se o modelo segregador das escolas do XVII, ou seja, a democratização total do ensino brasileiro ainda não ocorreu, por isso a necessidade de todos os profissionais envolvidos direta ou indiretamente com o processo de ensino/aprendizagem compreenderem que é preciso ocorrer a articulação entre o atendimento educacional especializado e o ensino regular, para então o processo de inclusão educacional e social ser exitoso.

Porém compreendemos que nenhuma pessoa sozinha conseguirá rever práticas arraigadas do sistema educacional brasileiro, todos deverão acreditar no poder transformador e libertador da educação (FREIRE, 1987), uma vez que não se muda a estrutura educacional em passe-de-mágica.

Segundo Sassaki (1999), a inclusão não deve ser somente na área educacional, o teórico propõe uma inclusão das pessoas com deficiências ao âmbito social, lazer, esportes e no sistema religioso, sendo todos esses aspectos assegurados pelas legislações, nesse sentido a implementação da Sala de Recursos Multifuncionais garante esclarecimentos e informações aos responsáveis sobre os reais direitos das pessoas com deficiências. 


\section{A infraestrutura e materiais disponíveis na sala de recursos multifuncionais - Arraial das Flores}

As escolas supramencionadas receberam verbas federais do Programa Dinheiro Direto na Escola (PDDE) Acessibilidade, no valor total de R \$ 10.000,00 sendo que R \$ 8.000,00 de custeio (materiais consumíveis) e R\$2.000,00 de capital (materiais permanentes), para aplicação da mesma foram seguidas as orientações do MEC presentes no Documento Orientador Programa Escola Acessível de 2013.

A verba do PDDE - Acessibilidade tem como objetivo;

Promover a acessibilidade e inclusão de estudantes com deficiência, transtornos globais do desenvolvimento e altas habilidades/superdotação matriculados em classes comuns do ensino regular, assegurando-lhes o direito de compartilharem os espaços comuns de aprendizagem, por meio da acessibilidade ao ambiente físico, aos recursos didáticos e pedagógicos e às comunicações e informações (BRASIL, 2013).

No ano de 2014 e 2015, a Diretora da Escola Guimarães Rosa no município de Arraial das Flores - SP, com experiência de doze anos no PDDE-Escola, apresentou dificuldade de informações sobre a verba em questão. Entramos em contato com a Secretaria Municipal de Educação de Arraial do Mar - SP (nome fictício), por conhecer o trabalho que a Secretaria desenvolveu em relação ao atendimento de alunos com deficiência, no intuito de obter informações, esclarecimentos de como proceder para o investimento da Verba recebida.

Obteve-se informação de que deveria fazer um Plano de Atendimento, no site do SIMEC - Sistema Integrado de Monitoramento do Ministério da Educação. Também houve necessidade de entrar em contato por telefone para maiores esclarecimentos, no Ministério da Educação Secretaria Executiva em Brasília, recebeu-se a informação que o Documento Orientador do Programa Escola Acessível, Manual do Programa Escola Acessível, Resolução No 19 de 21/05/2013, Resolução No 27 de 02/06/2011, e Resolução No 27 de 27/07/2012, solucionaria os problemas e tiraria as dúvidas.

Quando já tinha sido realizado o preenchimento dos dados da Escola, a diretora, precisou então elaborar o Plano de Atendimento, a ser postado no SIMEC. Ao entrar no Plano de Atendimento havia um campo descrito ação, com duas ações a serem escolhidas e, um campo descrito como itens financiáveis.

Na primeira ação havia a indicação “Aquisição de materiais e bens e/ou contratação de serviços para construção e adequação de rampas, alargamento de portas e passagens, instalação de corrimão, construção e adequação de sanitários para acessibilidade e colocação de sinalização visual, tátil e sonora", nesta ação os itens financiáveis são: mão de obra, material de 
construção, pia e vaso sanitário, placas e pisos táteis, projeto e outros, o programa pedia: selecione um ou mais itens financiáveis, sequencialmente.

Já na segunda ação havia a indicação "Aquisição de cadeiras de rodas, recursos de alta tecnologia assistiva, bebedouros acessíveis e mobiliários acessíveis", nesta ação os itens financiáveis são: bebedouro, cadeira de rodas, mesa e carteira acessível, recursos de alta tecnologia assistiva.

Após fazer reunião com o Conselho de Escola e levantamentos das necessidades da escola, iniciamos pela pesquisa de empresas que trabalham com materiais e produtos de acessibilidade.

Em nosso município, conseguimos somente materiais de construção, pois o atendente conseguiu fazer orçamento específico para os materiais necessários. Todos os outros produtos foram cotados em outras cidades da região nordeste e noroeste do estado de São Paulo, assim como empresas do Sul do País.

Vale ressaltar que o valor de $\mathrm{R} \$ 2.000,00$ de capital só daria para comprar o bebedouro acessível mais simples, sendo que precisávamos comprar uma cadeira de rodas e mesa acessível. Já com o piso tátil precisávamos de aproximadamente $180 \mathrm{mt}$, sendo que o custo somente da colocação orçava em $\mathrm{R} \$ 7.300,00$ fora os $180 \mathrm{mt}$ de piso tátil e, tínhamos de verba de custeio somente $\mathrm{R} \$ 8.000,00$.

Fizemos o possível para aplicar da melhor forma o valor recebido, atendendo exatamente o que a legislação prevê, mas as dificuldades foram muitas. Houve um saldo do valor recebido, pois a legislação limita de um jeito, que não deu para comprar o que indicava o Plano de Atendimento.

Este relato é para exemplificar algumas dificuldades que um diretor de escola enfrenta na aplicação do PDDE-Acessibilidade. Há necessidade de viabilizar a aplicação deste recurso, facilitar o trabalho, agilizar e não burocratizar, para atingir o objetivo proposto.

Vale ressaltar que alguns materiais não foram adquiridos, pois não fazem parte Programa Nacional de Implementação das Salas de Recursos, do governo federal, então os materiais pedagógicos necessários para complementar a prática docente foram adquiridos pela Secretaria Municipal de Educação, tais materiais estão relacionados em anexo. 


\section{Objetivos gerais do Atendimento Educacional Especializado no município de Arraial das flores}

- $\quad$ Possibilitar a educação inclusiva, permitindo que o educando tenho um processo de ensino/aprendizagem que lhe ofereça condições de igualdade no ensino regular.

- Permitir a integração dos profissionais da educação e a participação da comunidade escolar no acolhimento da pessoa com necessidades especiais.

\section{Objetivos específicos}

- $\quad$ Orientar os professores do ensino regular acerca da educação especial, sobretudo o AEE.

- Atender individualmente os estudantes com deficiência.

- Realizar estudos coletivos com os profissionais das unidades escolares que acolhem a sala de recursos multifuncionais.

- $\quad$ Orientar os responsáveis para o desenvolvimento global da criança.

\section{O ambiente para o Atendimento Educacional Especializado no município de Arraial das Flores}

Art. $5^{\circ} \mathrm{O}$ AEE é realizado, prioritariamente, nas salas de recursos multifuncionais da própria escola ou em outra de ensino regular, no turno inverso da escolarização, não sendo substitutivo às classes comuns, podendo ser realizado, em centro de atendimento educacional especializado de instituição especializada da rede pública ou de instituições especializadas comunitárias, confessionais ou filantrópicas sem fins lucrativos, conveniadas com a secretaria de educação ou órgão equivalente dos estados, do Distrito Federal ou dos municípios (BRASIL, 2009, p. 1).

O primeiro AEE em Arraial das Flores se deu na Escola Municipal Guimarães Rosa, a responsável por esse atendimento tem as habilitações exigidas pela legislação brasileira para o oferecimento dessa prática.

Vale ressaltar que a professora ficava dois dias no espaço reservado à sala para o AEE e três dias nas escolas, colhendo os dados, conversando, oferecendo as devidas orientações a profissionais da educação e responsáveis, como já fora mencionado nesse relato.

As anamneses foram constituídas a partir da compilação dos materiais acadêmicos oferecidos na disciplina de Avaliação e Intervenção I e II do curso de Educação Especial da Faculdade de Ciências e Letras - Campus Araraquara da Universidade Estadual Paulista - Júlio de Mesquita Filho (UNESP). 
As anamneses com os responsáveis foram feitas nas instituições de ensino, agendavase os dias e horários para a entrevista, durante essas conversas alguns pais desabafavam e pediam conselhos, ajudas, pois muitos se viam sozinhos em meio a seus sentimentos. Para que o acolhimento fosse dado de modo saudável, tudo era ouvido, compreendido, discutido, apresentando sugestões para possíveis soluções para alguns problemas, no entanto algumas anamneses demoraram mais de 6 horas, tendo que ser divididas em dois dias.

No ano de 2015 começaram os atendimentos na Escola Guimarães Rosa, houve AEE para 17 pessoas com deficiência, 4 crianças com síndrome de Down, 5 crianças com deficiências intelectual, 2 crianças surdas, 2 crianças com paralisia cerebral, 1 criança com baixa visão, 1 com Transtorno do Espectro Autista.

A sala de recursos tinha o horário flexível, teve AEE nos dois períodos, vespertino e matutino, às terças e quartas-feiras esse AEE ocorria no vespertino, os demais dias da semana ocorria no matutino. Vale ressaltar que durante os atendimentos os responsáveis acompanhavam as crianças, esses momentos eram aproveitados para oferecer as devidas orientações aos familiares.

No ano de 2016 a quantidade de crianças atendidas no AEE da Escola Guimarães Rosa foi reduzida para 10 crianças, sendo 2 com síndrome de Down, 1 surdo, 1 com baixa visão, 2 com deficiência intelectual, 2 com Transtorno do Espectro Autista, 1 com paralisia cerebral.

No começo do ano de 2016 a Escola Fernando Pessoa, passou a ter uma sala de Atendimento Educacional Especializado. Nos primeiros meses, fora feito a organização da sala de recurso, tal como cada espaço e materiais pedagógicos. Nesse período também foram realizados algumas reuniões com a professora da sala de AEE da Escola Guimarães Rosa, para conhecer os trabalhos com as crianças que, a partir de então, frequentariam a sala de recursos na Escola Fernando Pessoa. Após toda essa organização fora marcado uma reunião com os pais desses alunos, onde apresentamos a nova sala e professora. Pois essa sala de recursos multifuncionais teria suas atividades concentradas no período vespertino, enquanto a sala de recursos funcionais da Escola Guimarães Rosa passaria atender os estudantes apenas no turno matutino.

Esse atendimento tem como fundamento principal preparar os alunos para desenvolver habilidades e utilizar instrumentos de apoio que facilitem seu desenvolvimento. Sendo uma forma de desenvolver mais a interação social e diminuir as barreiras que impedem a inclusão, que infelizmente ainda são muitas.

Para que o atendimento seja eficaz é utilizado o concreto, com jogos pedagógicos que estimulam a aprendizagem, atividades de coordenação motora, táteis, sensoriais, atividades que 
estimulem a linguagem oral e a escrita, é feito um trabalho com as histórias contadas pela professora ou criada pelos alunos.

Os recursos da sala multifuncional da Escola Fernando Pessoa são necessários para o desenvolvimento da aprendizagem. Um exemplo eficaz são os softwares para comunicação assistiva, comunicação oral e estímulo para atividades diversas. Outro recurso muito significativo são os jogos pedagógicos no Tablet, com esses jogos os alunos têm mais estímulos de aprender as letras do alfabeto, por exemplo, uma vez que far-se-á uso do letramento lúdico. (SILVEIRA; PEREIRA, 2015)

Vale ressaltar que as professoras estabeleciam planos individuais para cada criança, já que as necessidades são diferentes, além da necessidade de adaptação curricular conjunta com os profissionais responsáveis pelo ensino regular.

Com esses recursos, o Atendimento Educacional Especializado na escola Fernando Pessoa foi muito relevante para a aprendizagem das crianças com deficiência que frequentaram as salas regulares, estimulando e ajudando a desenvolver suas habilidades e aprendizagens.

De acordo com o Decreto $\mathrm{n}^{\circ} 7611 / 2011$ as salas de recursos multifuncionais contaram com todas as especificações legais e equipamentos fornecidos pelo Ministério da Educação, como os já descritos acima, além dos materiais cedidos pelo MEC, houve a aquisição de materiais para a viabilização do AEE e adequação do espaço físico.

Estes atendimentos obcecaram as necessidades de cada educando, sendo necessário para isso fazer anamneses, entrevistas com pais e professores para o conhecimento dos sujeitos e organizações de planos de atendimentos individuais, pois se sabe que cada pessoa é dotada de especificações únicas não sendo todos igualitários. Vale ressaltar que as crianças participantes do Atendimento Educacional especializado têm o transporte público para levalas de e para suas respectivas residências.

\section{Método utilizado durante o AEE}

É sabido que em educação especial os métodos utilizados são aqueles que mais se aproximem das necessidades e limitações dos educandos, então traçar ou definir uma única metodologia de trabalho não condiz a prática docente em educação especial, durante os atendimentos os métodos são mesclados pensando exclusivamente no desenvolvimento cognitivo.

Entretanto podemos afirmar que o método que cerceou a nossa prática foi o método Decrolly, este método foi desenvolvido a partir das associações das ideias, que é baseado nas 
necessidades e centro de interesses da criança, centro para o qual deveriam convergir e de onde divergiriam todas as ideias.

Sua teoria se fundamenta numa concepção psicobiológica e social, merecendo destaque, dentre estes aspectos, o psicológico. O método Decrolly tem três fases, a observação, associação e expressão.

De acordo com o pensamento de Decroly, para que a observação possa contribuir para as etapas posteriores e para desenvolver a mente dos alunos é preciso que o professor selecione os temas possíveis, que sejam compatíveis ao desenvolvimento e desejo dos estudantes para que os interesses sejam ativados.

Por meio da associação relacionam-se noções adquiridas pela observação aos objetos e aos fatos, próximos ou longínquos (espaço), atuais e passados (tempo), no que diz respeito à adequação do objeto as necessidades do homem (tecnologia), e aquilo que se refere a causa e efeito, estimulando o pensamento crítico e dando início ao processo de formação do hábito de pensar das crianças.

A expressão no método Decroly engloba tudo aquilo que permite a "expressão do pensamento" de forma acessível aos outros. Seja através da fala ou escrita, desenhos, trabalhos manuais, desde que relacionados aos centros de interesse em estudo, baseada nas postulações do documento São Paulo (1985).

Nesse sentido os centros de interesse encaminham o educando a uma aprendizagem efetiva, pois todo o processo é focado nos interesses dos estudantes, respeitando suas individualidades.

Além dessa metodologia, durante a prática docente, utilizamos os métodos sintéticos e analíticos de alfabetização, enfatizando o método fônico, em relação ao raciocínio lógico matemático utilizamos atividades de problematização e resolução de situações problemas com a utilização de materiais, ou seja, jogos.

\section{Cronograma de atividades do Atendimento Educacional Especializado}

O atendimento educacional especializado ocorreu com cronograma de atividades, sendo individual, de forma a fornecer suporte necessário as necessidades educacionais especiais dos educandos, consoante a área especifica, favorecendo seu ao acesso ao conhecimento.

Esse cronograma de atividades foi flexível, organizado, reorganizado sempre que necessário, de acordo com as necessidades dos educandos, sendo que todas as atividades 
desenvolvidas nesse cronograma tiveram anuência da direção e equipe pedagógica da unidade de ensino.

Esse atendimento se iniciou com a realização de Anamnese com os responsáveis dos estudantes e com os professores, como já mencionado, com aplicações do Instrumento de Avaliação do Repertorio Básico para Alfabetização (IAR) para se conhecer as habilidades infantis.

Após as avaliações diagnósticas se iniciou a orientação pedagógica, a fim de auxiliar os professores do ensino regular, mas infelizmente com a escassez de tempo nem todos os professores das dezessete crianças tiveram as devidas orientações pedagógicas, é importante frisar que a ausência de tempo se deu pela não aceitação por parte da equipe técnica da Secretaria de Educação da instauração do AEE - Itinerante, aquele que possibilita que o professor do AEE vá até a escola da criança para acompanha-la e oferecer orientações a pais, professores e toda equipe escolar.

As atividades pedagógicas desenvolvidas no AEE ocorreram semanalmente no contra turno das atividades do ensino regular do educando, ou seja, os horários respeitaram as necessidades escolares e ambulatoriais dessas crianças. Há crianças que iam acompanhadas pelos seus responsáveis, assim havia um contato direto com a família, podendo esta ser orientada semanalmente, sendo esse elo fundamental para o êxito do AEE.

\section{Carga horária}

Cada atendimento individualizado tem a duração de uma hora e meia, não podendo ultrapassar duas horas por atendimento.

A carga horária do professor responsável pela sala multifuncional é de 40 horas semanais divididas em AEE e Atendimento a pais e professores, sendo assim 30 horas em AEE, e as demais horas livres foram destinadas a preparo, estudos de atividades ao AEE, preenchimento de fichas e relatórios, podendo ocorrer na unidade que oferta a sala multifuncional, Secretaria da Educação, ou em ambiente facilitador para tal prática.

Nesse sentido os horários são definidos da seguinte forma:

Quadro 1 - Turnos

\begin{tabular}{|l|l|}
\hline \multicolumn{1}{|c|}{ UNIDADE ESCOLAR } & \multicolumn{1}{c|}{ PERÍODO } \\
\hline E.M. Fernando Pessoa & Vespertino \\
\hline E.M. Guimarães Rosa & Matutino \\
\hline
\end{tabular}

Fonte: Elaborado pelas autoras 


\section{Avaliação}

A prática avaliativa no ambiente escolar permite ao profissional escolher os mais diversos procedimentos, será algo contínuo, ou seja, será processual, ocorrendo durante os atendimentos. Entrevistas, jogos, análise da produção do aluno, entre outros, a fimm de confrontar dados, resultados e efetuar uma análise detalhada.

De acordo com Luckesi (2005) a avaliação consiste em:

- Verificar quais contextos socioculturais em que se encontra inserido o estudante.

- $\quad$ Perceber o desenvolvimento motor, cognitivo, sócio afetivo e escolar do estudante.

- $\quad$ Encontrar as melhores estratégias de aprendizagem utilizadas pelo estudante.

- Identificar a metodologia utilizada pelo professor, nas intervenções no dia a dia.

- Validar os conhecimentos tácitos (prévios) que o aluno manifesta em sala de aula, assim como as dificuldades/necessidades individuais, em relação aos novos conteúdos de aprendizagem.

Entrevistas (anamneses): foram realizadas com todos os envolvidos, professor(es), direção, equipe pedagógica, porém as anamneses familiares foram consideradas essenciais para o conhecimento de quem é o estudante, para então traçar planos individuais de ensino, as informações acerca da dificuldade, limitações e deficiências apresentadas constituíram a prática docente, nesse sentido a partir dos dados colhidos avaliou-se como se daria o cotidiano no AEE.

As observações dos estudantes, durante a aplicação do IAR permitiram a análise do problema no contexto escolar, assim teve-se mais um elemento para a constituição dos planos individuais de ensino.

Após todo esse trabalho descrito, no final de cada semestre tem-se a elaboração de um Relatório Individual do desempenho, sendo nele descrito tudo o que fora observado e feito pelos estudantes durante o AEE, além desse relatório feito semestralmente, era feito o semanário individual, em cujo as atividades eram descritas em tópico, nesse mesmo espaço, realiza-se os registros do ocorrido permitindo que a professora, avalia além das ações discentes, esse registro desencadeia a avaliação e reflexão da prática docente. 


\section{Considerações finais}

Em consonância com as propostas legais para a implementação da sala de recursos, este relato de experiência auxilia na compreensão de alguns aspectos pedagógicos para o AEE.

Entretanto foram relatadas todas as etapas para que a sala do AEE fosse colocada em prática, tal como a infraestrutura e os materiais para a sala, como é o espaço, o público alvo atendido, a carga horária, a avaliação e como foram realizadas as atividades em sala.

Dado o exposto, vemos o quanto é essencial a sala de Atendimento Educacional Especializado para que a educação seja inclusiva e o quanto é relevante que essas crianças tenham suas aprendizagens ressaltadas por meios pedagógicos como: jogos e atividades concretas, além da tecnologia assistiva.

Por todos esses aspectos, se as relevâncias aqui discutidas forem postas em práticas por todos os profissionais comprometidos e envolvidos no processo educativo, a probabilidade de êxito aumentará a cada AEE. Nesse sentido o sujeito atendido nessa sala de recursos multifuncionais terá condições mínimas de inclusão no ambiente escolar e na sociedade sem ônus.

\section{REFERÊNCIAS}

\section{BRASIL. Documento orientador programa implantação de salas de recursos}

multifuncionais. Brasília, DF: Ministério da Educação; Secretaria de Educação Continuada, Alfabetização, Diversidade e Inclusão Diretoria de Políticas de Educação Especial, 2013.

BRASIL. Documento Orientador Programa Escola Acessível de 2013. Brasília, DF: Secretaria de Educação Continuada, Alfabetização, Diversidade e Inclusão, 2013.

BRASIL. CNE. CEB. Resolução n. 4, de 2 de outubro de 2009. Que institui diretrizes operacionais para o atendimento educacional especializado na educação básica, modalidade educação especial. Brasília, DF: CNE; CEB, 2009.

DALHEM, L. EI método Decroly aplicado a la escuela. Madrid: Cuidad Lineal, 1925.

FREIRE, P. Pedagogia do oprimido. Rio de Janeiro, Paz e Terra. 1987.

LUCKESI, C. C. Avaliação da aprendizagem na escola: reelaborando conceitos e recriando a prática. 2. ed. Salvador: Malabares, 2005.

MANTOAN, T. E. Todas as crianças são bem vindas à escola. Laboratório de Estudos e Pesquisas em Ensino e Reabilitação de Pessoas com Deficiência - LEPED/ FE/ Unicamp. Disponível em: http://www.pro-inclusao.org.br/textos.html\#topo. Acesso em: 12 nov. 2009. 
MANTOAN, T. E. Integração X Inclusão: escola de qualidade para todos. Laboratório de Estudos e Pesquisas em Ensino e Reabilitação de Pessoas com Deficiência - LEPED/ FE/ Unicamp. Disponível em: http://www.pro-inclusao.org.br/textos.html\#topo. Acesso em: 12 nov. 2009.

PARANÁ (ESTADO). Glossário: termos importantes em educação especial. Curitiba: Departamento de Educação Especial e Inclusão Educacional, 2013.

SÃO PAULO (ESTADO). Método de centro de interesse: sugestões metodológicas para o ensino de deficientes mentais educáveis. São Paulo: Coordenadoria de estudos e normas pedagógicas, 1985.

SASSAKI, R. K. Inclusão: construindo uma sociedade para todos. 3. ed. Rio de Janeiro: WVA, 1999.

SILVEIRA, A. P.; PEREIRA, A. J. B. Programa Nacional de Alfabetização na Idade Certa: intenções nacionais ou internacionais? In: V CONGRESSO BRASILEIRO DE EDUCAÇÃO, 5., 2015, Bauru. Anais [...]. Bauru, SP: UNESP, 2015. Disponível em: http://www2.fc.unesp.br/cbe/files/anais_V_CBE.pdf Acesso em 09 de jun. 2019.

\section{Como referenciar este artigo}

SILVEIRA, A. P.; SILVA, A. M.; MORCELI, Â. M. MONTEIRO, D. C. Implementação das salas de recursos multifuncionais: tempos vividos e vivenciados. Temas em Educ. e Saúde, Araraquara, v. 16, n. 2, p. 705-719, jul./dez. 2020. e-ISSN 2526-3471. ISSN 1517-7947. DOI: https://doi.org/10.26673/tes.v16i2.13471

Submetido em: 21/03/2020

Revisões requeridas: $05 / 06 / 2020$

Aprovado em: 15/07/2020

Publicado em: 27/08/2020 